\title{
Prevalence of androgen deficiency in aging male in an outpatient population and effects of testosterone gel reposition therapy
}

\section{Prevalência de deficiência de androgênio em homens idosos em uma população ambulatorial e efeitos da terapia de reposição de testosterona em gel}

Victor Ferro Borges ${ }^{1 *}$, Michel Hamui Sallum ${ }^{1}$, Camila Eriane Antunes ${ }^{1}$, João Arthur Pelegrinelli Thirone ${ }^{1}$, Fernanda Oliveira Magalhães ${ }^{2}$, Sergio Anacleto da Silva ${ }^{2}$, Douglas Reis Abdalla $^{1,3}$, Ana Cláudia Pelegrinelli ${ }^{2}$

\begin{abstract}
RESUMO
Contexto: A deficiência de androgênio no envelhecimento masculino (ADAM) é caracterizada pelo hipogonadismo com sintomas como redução do desejo sexual, perda de massa muscular, entre outros. O tratamento com gel de testosterona e os resultados em torno do peso e outros indicadores são os objetos de pesquisa. Objetivo: Analisar a associação entre o ADAM e a obesidade na população ambulatorial estudada e verificar os resultados do tratamento com gel de testosterona. Materiais e métodos: De um grupo de 126 pacientes ambulatoriais do Hospital Universitário Mário Palmério, 40 foram selecionados com testosterona total inferior a $300 \mathrm{ng} / \mathrm{dL}$, mediante a assinatura de um termo de consentimento livre e esclarecido por escrito e a realização de testes laboratoriais. Após nova dosagem de testosterona e avaliação urológica, 6 pacientes foram tratados por um tempo médio de 6 meses. Inicialmente a dosagem era de $50 \mathrm{mg} / \mathrm{dia}$, com consultas médicas e testes laboratoriais para verificar os efeitos e ajustar a dosagem. As variáveis analisadas foram IMC, circunferência abdominal, peso, massa muscular, gordura corporal e visceral, além das dosagens de soro de testosterona, perfil lipídico, entre outras, considerando o teste t entre o início e o final do tratamento, definindo o nível de significância por $\mathrm{p}<0,05$. Resultados: Aumento significativo dos níveis de testosterona total $(\mathrm{p}<0,001)$ e uma tendência de melhora dos níveis de testosterona livre $(\mathrm{p}=0,061)$ e nenhuma redução significativa do IMC $(\mathrm{p}=0,4308)$, circunferência abdominal $(\mathrm{p}=0,1695)$, peso $(\mathrm{p}=0,999)$, gordura corporal $(\mathrm{p}=0,194)$ e massa muscular $(\mathrm{p}=0,632)$, enquanto a gordura visceral aumentou $(\mathrm{p}=0,5265)$. A vitamina $\mathrm{D}$ não teve aumento significativo $(\mathrm{p}=0,2422)$. Conclusão: $\mathrm{O}$ nível total de testosterona foi aumentado após o tratamento com gel de testosterona com significância estatística, entretanto, deve haver novas pesquisas com mais sujeitos com ADAM para provar os benefícios deste tratamento.
\end{abstract}

Palavras-chave: Carência de androgênio; Envelhecimento masculino; Obesidade; Testosterona.

\section{ABSTRACT}

Background: Androgen deficiency in aging male (ADAM) is characterized by hypogonadism with symptoms such as reduced sexual desire, muscle mass loss, among others. The treatment with testosterone gel and the results around weight and other indicators are the research objects. Objective: Analysis of association between ADAM and obesity in the outpatient population studied and to verify the outcomes of the testosterone gel treatment. Materials \& Methods: From a group of 126 outpatients of University Hospital

\footnotetext{
${ }^{1}$ Medicine Students, University of Uberaba (UNIUBE), Uberaba, MG, Brazil.

*victorfborges@gmailcom.

${ }^{2}$ Medicine Professor, University of Uberaba (UNIUBE), Uberaba, MG, Brazil.

${ }^{3}$ Health Science Professor, Faculty of Human Talents (FACTHUS), Uberaba, MG, Brazil.
} 
Mário Palmério, 40 were selected with total testosterone lower than 300ng/dL, upon the signature of written informed consent form and the realization of laboratory tests. After new testosterone dosage and urologic evaluation, 6 patients were treated for an average time of 6 months. Initially the dosage was $50 \mathrm{mg} / \mathrm{day}$, with medical consultations and laboratory tests to verify the effects and to adjust the dosage. The variables analyzed were BMI, abdominal circumference, weight, muscle mass, body and visceral fat, in addition to testosterone serum dosages, lipid profile, amongst others, considering the test $t$ among the beginning and end of treatment, defining the significance level by $\mathrm{p}<0,05$. Results: Significant increase of total testosterone levels $(\mathrm{p}<0,001)$ and a tendency of improvement in the free testosterone levels $(\mathrm{p}=0,061)$ and no significant reduction of BMI $(p=0,4308)$, abdominal circumference $(p=0,1695)$, weight $(p=0,999)$, body fat $(p=0,194)$ and muscle mass $(p=0,632)$, while visceral fat increased $(p=0,5265)$. Vitamin $D$ had no significant increase $(\mathrm{p}=0,2422)$. Conclusion: The total testosterone level was increased after the testosterone gel treatment with statistical significance, however there must be new research with more subjects with ADAM to prove the benefits of this treatment.

Keywords: Androgen deficiency; Aging male; Obesity;Testosterone.

\section{INTRODUCTION}

The androgenic deficiency of aging male (ADAM) is a clinical syndrome characterized by low testosterone levels associated with symptoms and clinical signs of hypogonadism, which may include reduced sexual impulse, decreased libido, erectile dysfunction, reduced beard and hair growth, muscle mass loss, gynecomastia and increased body fat (HARMAN et al., 2001; MARTINS et al., 2014).

The decrease in testosterone levels with aging has already been demonstrated in several cross-sectional and longitudinal studies, such as the European Male Aging Study (EMAS), so that the decline in hormonal levels would begin to occur in the Third Decade of Life and would have a very slow progression. The syndrome would be characterized when presenting the symptoms and the prevalence estimated by EMAS of $2.1 \%$ of late hypogonadism in the population, which is much lower than the prevalence of decreased testosterone levels with age advancing, estimated at $20 \%$ after 60 years and $50 \%$ after 80 by longitudinal studies (HARMAN et al., 2001).

The hypogonadism may be primary, secondary or mixed, so that the primary is the result of testicular disorders, diagnosed by high values of LH and FSH with reduced testosterone. The secondary is the result of hypothalamic or pituitary disorders, with normal or reduced levels of LH and FSH associated with the testosterone decrease, while the mixture can be the result of both mechanisms. It is important to differentiate the ADAM of other secondary causes of classical hypogonadism, such as testicle diseases or hypothalamus-pituitary axis diseases (SURAMPUDI; WANG; SWERDLOFF, 2012). 
The most prevalent hypogonadism in middle-aged adult males is the secondary or the mixed, which pathophysiology results from several mechanisms, including: Leydig cells function decrease, hypothalamus-pituitary axis function decline with circadian variation loss, increased levels of SHBG with age, changes in the testosterone receptors, among others (WYLIE; FROGGATT, 2010; MARTINS et al., 2014).

The effects of ADAM result in an important life quality loss in much of the male population with aging, being important its identification and diagnosis, even though generating a certain fear from part of these men, whom mostly do not look for any treatment. It is not a syndrome that narrows down to erectile dysfunction or a single symptom, but to a set of them, which often culminate in the loss of vitality and encouragement, sometimes leading to depression and the in productivity decrease (WANG et al., 2008, SURAMPUDI; WANG; SWERDLOFF, 2012).

Among the metabolic changes associated with ADAM, obesity stands out, so that in obese men in mild to moderate degrees, the levels of SHBG are decreased, leading to the decrease of the total testosterone values, initially keeping those of free testosterone. This is due to the increase in circulating insulin, which inhibits the production of the SHBG, so that the weight increase in men can accelerate the decrease rate of testosterone levels (WYLIE; FROGGATT, 2010; SURAMPUDI; WANG; SWERDLOFF, 2012).

The androgenic deficiency then, when confirmed, can be treated by the testosterone replacement, with the intention to normalize the hormone levels and promote the improvement of the various clinical aspects influenced by the syndrome. Testosterone is found in several formulations, with pharmacokinetics and different presentations on the market, functioning as a pro-hormone as well, with the peripheral conversion in dihydrotestosterone (DHT) and estradiol (HARMAN et al., 2001; SURAMPUDI; WANG; SWERDLOFF, 2012).

Among the available formulations are oral derivatives (discouraged due to hepatotoxicity), injectable forms, transdermal and buccal adhesives and testosterone gel. There are two main options of testosterone gel, Androgel and Testim, being a good option in the treatment of ADMA due to the ease of application and the ease of posology. These medications also promote an increase in the relationship between DHT and testosterone (HARMAN et al., 2001; SURAMPUDI; WANG; SWERDLOFF, 2012; MARTINS et al., 2014). 
The use of androgen consists of anabolic therapy for the limitations and signs inherent in aging, but also associated with ADAM. The replacement of testosterone gel and its impacts on the clinical variables influenced by ADAM, aiming at an improvement in life quality considering also the implications on the obesity framework and other clinical indicators are the objects of this study, demonstrating the possible viability of this medication as an option in the treatment of late hypogonadism (MARTINS et al., 2014).

The aim of this study is to verify the effects of the ADAM treatment with hormone replacement of testosterone in the form of gel, analyzing the impacts of the treatment on physical indicators and the Association of the framework with obesity in an outpatient population, evaluating success in the use of this medication in obtaining clinical improvement.

\section{METHODOLOGY}

The study was carried with specific research outpatients at the University Hospital Mário Palmério (MPHU), whom were subjected to laboratory examinations and initial clinical evaluation after signing written informed consent form (WICF), occurring between March 2014 and March 2016. In a group of 126 patients, the results of laboratory tests were obtained, among which the values of total testosterone and free testosterone, in addition to routine exams in search of comorbidities.

From that group, 40 patients that presented total testosterone values below 300ng/DL were selected. These patients were subjected to clinical evaluation, applying the ADAM survey as part of the anamnesis, in addition to redoing the laboratory tests with a new dosage of testosterone and doses of $\mathrm{LH}, \mathrm{FSH}$ and prolactin, in order to confirm the ADAM and discard other secondary causes. The clinical evaluation also included weight, BMI and abdominal circumference, allowing the identification of patients with obesity and overweight, and the possible association with ADAM.

The use of surveys developed for aid in the diagnosis of male hypogonadism presents low specificity and many guidelines do not recommend the use, but present high sensitivity, allowing the identification of symptoms. The isolated value of these surveys such as ADAM (Androgen Deficiency in Aging Male) is relative to the diagnostic confirmation of ADAM and should be combined with the use of testosterone dosage (Morley et al., 2006). 
Once diagnosis was confirmed, the patients underwent a urology evaluation, including PSA dosage, considering that the counter indications to the testosterone administration are in accordance with the risk of adverse consequences. The conditions in which there is very high risk are metastatic prostate cancer and breast cancer. The conditions under which there is a moderate risk of adverse consequences are PSA > 4 (> 3 in patients with high risk of prostate cancer, such as blacks and family history of first degree), hemopoiesis, severe urinary symptoms associated with benign prostatic hypertrophy and congestive heart failure not properly controlled (Bashin et al., 2010).

Figure 1 - Laboratory diagnosis of late hypogonadism and ADAM.

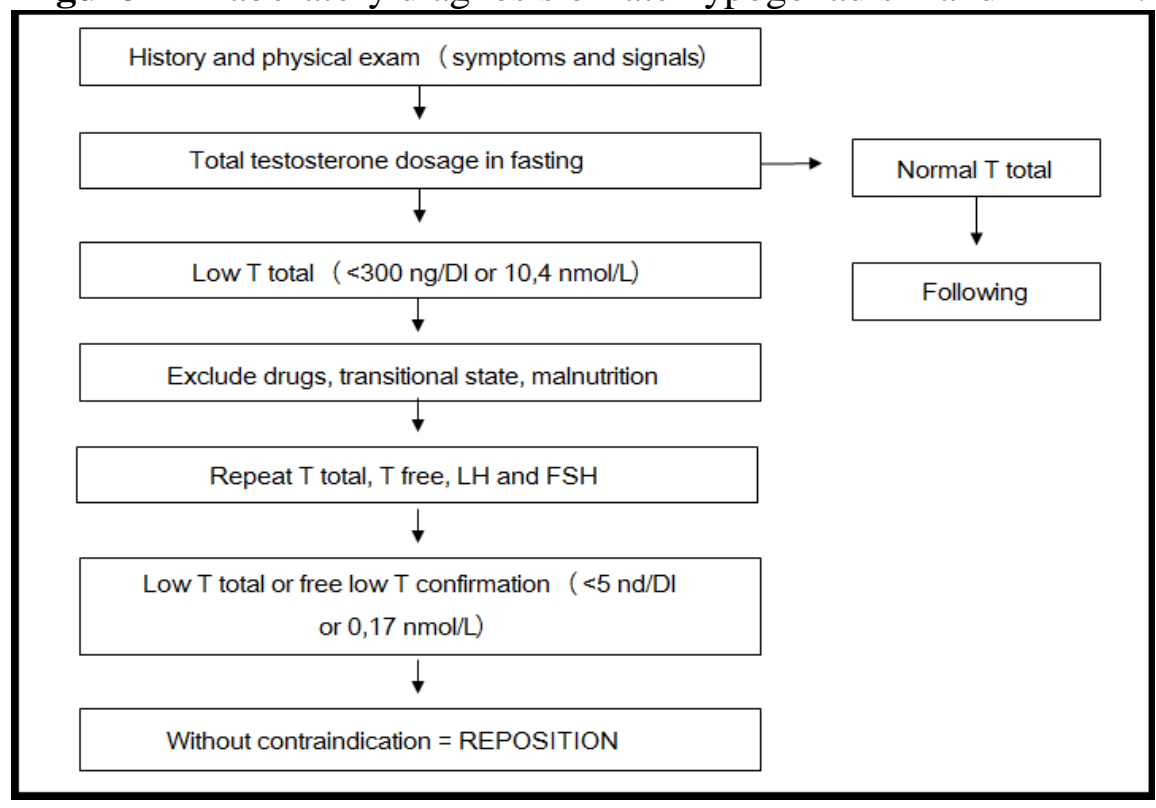

Source: adapted from Liberman, Garcia \& Figueira, 2011

As urology released the patients, the treatments started with the use of testosterone gel, always experiencing some difficulties related to the adherence of patients, with a large number of dropouts, difficulty in locating them after some time, besides those who had not received liberation from urology. The treatment with the gel was carried out in 6 patients in a avarange time of 6 months. It was initiated with the application of $50 \mathrm{mg} / \mathrm{day}$ of the testosterone gel, the dose adequacy being made by laboratory analysis performed monthly. The applications were made in the abdomen and thighs.

The patients' monitoring was with monthly consultations in the specific research clinic of MPHU, always repeating the hormone dosages and all laboratory routine exams performed from the beginning. In all consultations, bioimpedance was performed, with weight analysis, body mass index (BMI), abdominal circumference, body fat percentage, muscle mass and visceral fat. 
The values analysis was made for the 6 patients at the beginning and at the end of the treatment in a comparative way, using the T-Test pared, although the indicators have been verified in all monthly queries. The significance was defined by Alpha $=5 \%$. The initial data analysis, referring to the total group of patients with the studies of prevalence of obesity and other factors was made by the chi-squared test, with significance defined by Alpha $=5 \%$.

\section{RESULTS}

The analysis about to the total population studied showed a 31,7\% hypogonadism prevalence with total testosterone levels lower than 300ng/DL in a group of 126 patients. The overweight prevalence was $41,9 \%$, while the obesity prevalence was $37.5 \%$, including all patients with BMI above 30, in a group of 124 patients of whom the weight and BMI data were available. The association between obesity and ADAM in the prevalence study was not significant, with $p=0,272$.

The hypogonadism prevalence in the population studied was $31,7 \%$, which is high, so that not all 40 of the 126 patients could be defined as carriers of ADAM considering that this is a syndrome, which should present clinical repercussions.

At the end of the treatment, it was possible to monitor the indicators of 6 patients using the testosterone gel, and the results were evaluated at the beginning and at end of the treatment, with a duration of 6 months to 1 year. It was possible to measure weight, BMI, waist circumference, body fat percentage, muscle mass and visceral fat.

In addition to the bioimpedance analysis data, in all monthly consultations, the ADAM questionnaire was redone, which, although subjective, complemented the clinical evaluation, so that, from the 6 patients, only 2 reported an effective improvement in sexual performance and libido, data that indifferently remained to the other 4 patients.

This study analysed the following anthropometric characteristics before and after the testosterone gel application, as shown in figure 2: weight (figure 2A), BMI (figure 2B), muscle mass percentage (figure 2C), body fat percentage (figure 2D), abdominal circumference (figure 2E) and visceral fat (figure 2F).

The BMI decrease was expected since it involved body fat loss and muscle mass gain, both caused by the increasement of the testosterone level. However the results of the measurements performed revealed no significant difference with BMI reduction by 
the paired $\mathrm{T}$ test, comparing the data at the beginning and at the end of the treatment, presenting results $(30,835 \pm 2,3193$ vs $30,450 \pm 2,6764)$ with $\mathrm{p}=0,4308$.

The paired analysis of the month data to the body fat percentage did not present significant difference $(31,250 \pm 4,0243$ vs $32,033 \pm 3,0091)$, with $\mathrm{p}=0,194$, different from the expected, as well as the muscle mass percentage $(30,433 \pm 2,1639$ vs $30,250 \pm$ $2,1126)$, which showed $p=0,632$. Both results did not meet what was expected at the beginning of the treatment, which would be a significant body fat reduction and a muscle mass gain.

The other result that did not achieved what was expected was the patients weight variation, that showed no reduction with significant difference by $\mathrm{t}$ test paired between the beginning and the end of the treatment, $(87,600 \pm 8,8661$ vs $87,600 \pm 9,4969)$ with $p$ $=0,999$. The reduction was expected concomitantly with body fat reduction and muscle mass increase, fact that was not confirmed.

Figure 2 - A - weight, B - BMI, C - muscle mass percentagem, D - body fat percentagem, $\mathrm{E}$ - abdominal circumference, $\mathrm{F}$ - visceral fat.
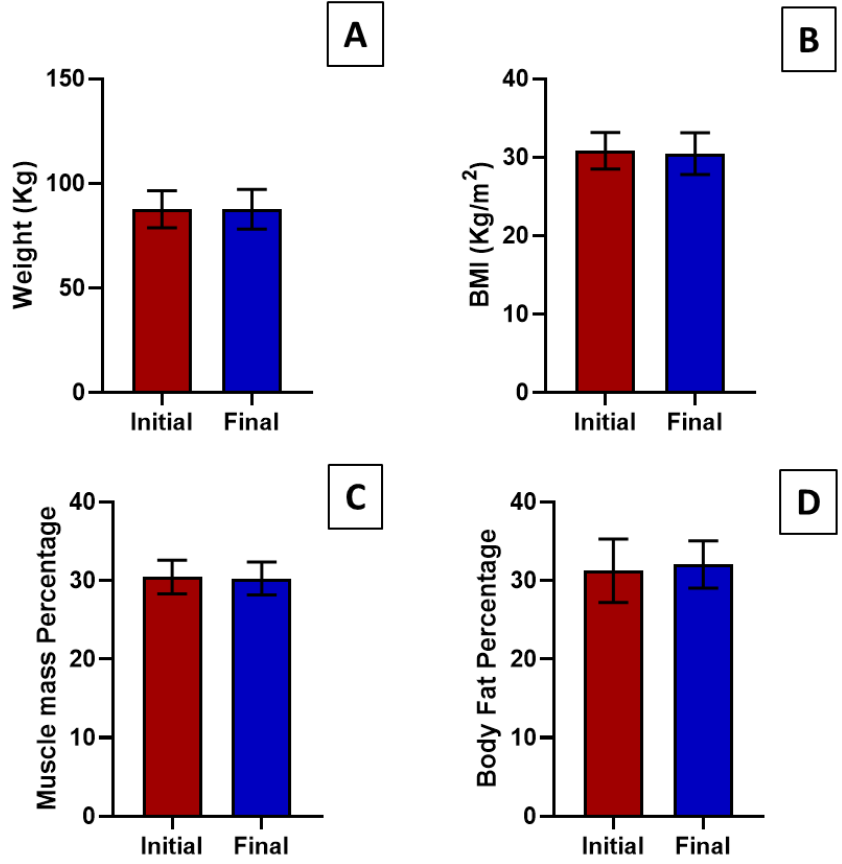

C
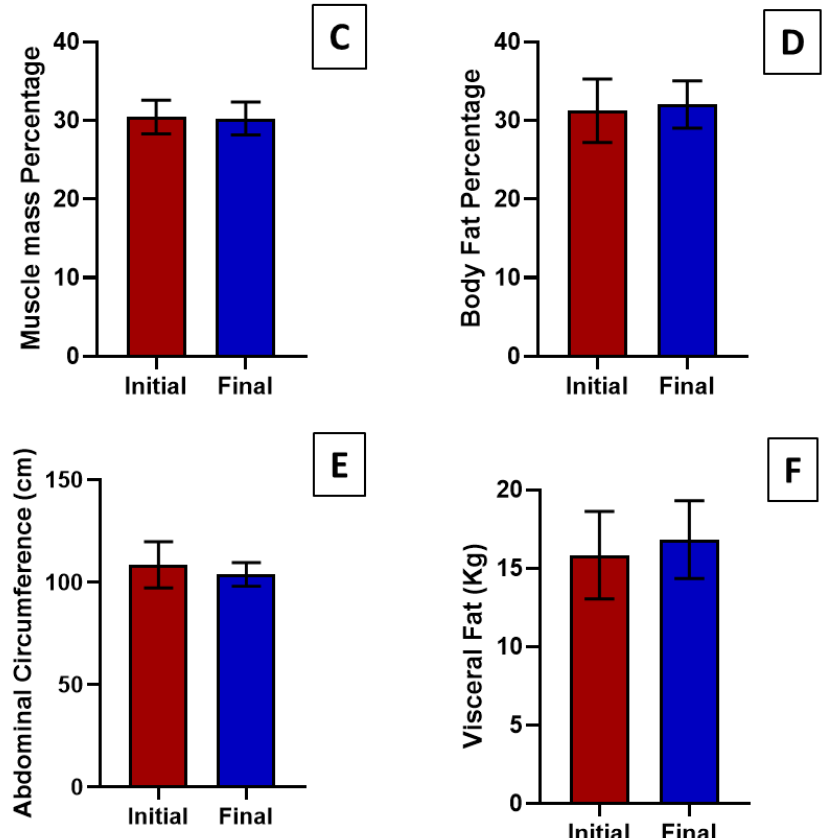

E

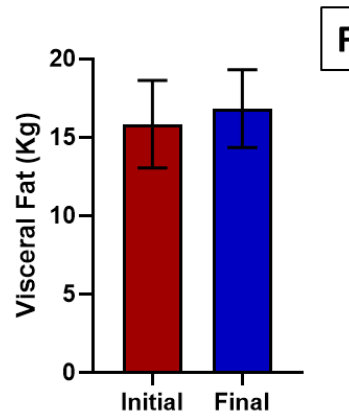

Source: Authors, 2021. 
The abdominal circumference also showed reduction with no significant difference in the patient's treatments, although it was expected, being an important indicator, including for the diagnostic of the metabolic syndrome. The result $(108,67 \pm$ $11,325$ vs $103,92 \pm 5,731)$ of the paired t test was $p=0,1695$.

Unlike expected, the patient's visceral fat showed an increase, however with no significant difference, being the result $(15,83 \pm 2,787$ vs $16,83 \pm 2,483)$ of the paired $t$ test $p=0,5265$. A significant reduction of this indicator with hormone reposition was expected at the beginning of the treatment.

Considering the laboratorial variables, the results followed what was expected in the analyzed parameters. The total testosterone and the free testosterone values, figure 2 , used during the periodic monitoring influenced in the increase of the final average, but with big discrepancies and the result was significant with $\mathrm{p}<0,001$ for total testosterone $(257,17 \pm 19,984$ vs $569,00 \pm 42,6918)$, figure $3 \mathrm{~A}$, and $\mathrm{p}=0,061$, for free testosterone $(5,4283 \pm 1,85962$ vs $11,245 \pm 8,2283)$, figure $3 \mathrm{~B}$, showing tendency to increase free testosterone.

Figure 3 - A - total testosterona, B - free testosterone
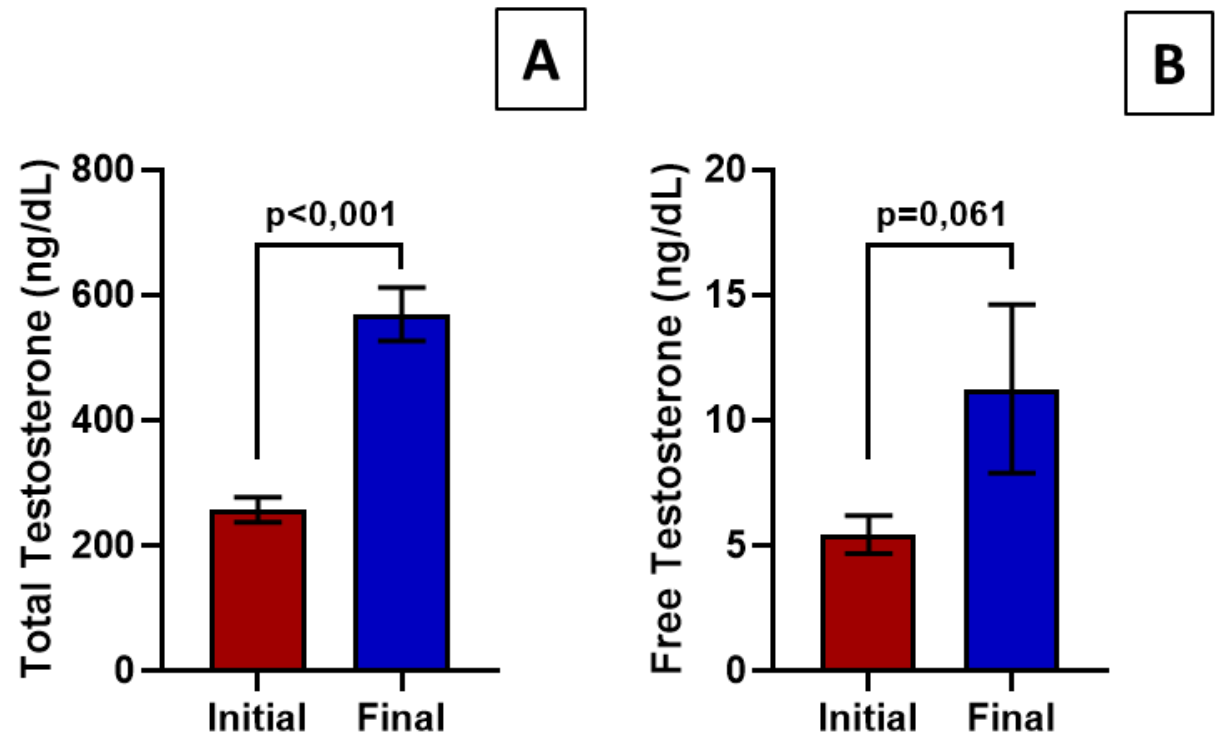

Source: Authors, 2021.

Between the analyzed laboratorial variables, the D vitamin dosage showed increase with no significance $p=0,2422(41,433 \pm 16,4870$ vs $46,817 \pm 10,1932)$. It was expected a possible improvement of the vitamin D levels and a possible androgenic reposition repercussion with improvement in cases of insufficiency $(<30 \mathrm{ng} / \mathrm{mL})$ or deficiency $(<20 \mathrm{ng} / \mathrm{mL})$ of this vitamin. 
The other laboratorial parameters searched did not find significance in comparison with $t$ test paired between the initial and final values of the study, which includes glicemia $(104,83 \pm 26,385$ vs $96,17 \pm 14,162)$ with $\mathrm{p}=0,247$, HDL cholesterol $(39,00 \pm 11,524$ vs $39,50 \pm 10,559)$ with $\mathrm{p}=0,4695$ and triglycerides $(109,00 \pm 36,508$ vs $127,33 \pm 44,925)$ with $\mathrm{p}=0,2280$. That does not allow the association with all the criteria of the metabolic syndrome, despite the correlation with abdominal circumference having been evidenced before in this study.

\section{DISCUSSION}

A multicentric study that evaluated similar variables made in the United States of America, which physic variables were reunited in Waltham, Massachusetts, showed that the hormonal reposition with testosterone gel should be effective in promoting sexual function, humor, muscle mass and lean mass increase, besides body fat decrease. But it did not show a significant difference in the group that used 50mg/day of the gel, just in the doses of $75 \mathrm{mg}$ and $100 \mathrm{mg}$. The lean mass increase presented $\mathrm{p}=0,0002$ in the group in use of $100 \mathrm{mg} / \mathrm{day}$, while the body fat decreased in all the groups of patients in testosterone gel treatment with $\mathrm{p}=0,0065$ by 90 days of treatment (WANG et al., 2000; WU et al., 2010).

This study was done with a group of 227 patients in treatment, being these variables evaluated in 168, considering the equipment and the patients' availability. Besides these factors, the muscular strength of these patients in use of testosterone was still monitored, so from the 227, 73 were using $50 \mathrm{mg} /$ day and 78 with $100 \mathrm{mg} /$ day, being the results measured after 90 and 180 days. The results were as expected in the muscular strength and body composition increase (WANG et al., 2000; WU et al., 2010).

Throughout the present study, many oscillations in the dosage of serum testosterone were observed, although it should be reminded that other variables can interfere in this result, such as the poor adherence of some patients and even the inadequate usage, with the application of different dosages or irregular usage, which are very common difficulties in long-term treatment.

Wang's same multicentric study also did not show a significant difference in HDL and triglycerides values, although having demonstrated a decrease in the total cholesterol levels (WANG et al., 2000; WU et al., 2010). 
A recent study published in Poland did not find significant results in the testosterone reposition on vitamin D levels in patients with congenital hypogonadism, although it found a significant alteration in the growth factor levels of fibroblasts 23 , which should be responsible for the regulation of the bone metabolism. This result differs of what was expected by the study in question and what was found in this present study (HAYMANA et al., 2017).

Although the results did not correspond to the expectation, the testosterone reposition by transdermal via still is an option in many studies, considering it to be a way of administering the hormone in discreet dosage and with controlled systemic absorption, lowering possible side effects. The delay in presenting clinical results can guide the patients to reluctance in maintaining the treatment, because the improvement of both clinical and laboratorial results should be in long term (ULLAH; RICHE; KOCH, 2014).

Considering the difficulties with the adhesion of patients, there were a lot of withdraws as the project occurred, being difficult to contact some of the patients. The total of 6 treated patients is a restrict number and makes it susceptible to other variables, often inherent to the project's control, like the usage of adequate medication and changing in habits of life.

The expected effects of an adequate treatment with hormone reposition would be muscle mass increase and reduction of body and visceral fat, besides the significant increase in testosterone levels, decrease of glucose and improvement of the glycemic and lipid profile of the patients. It is known that previous studies achieved these benefits with testosterone gel reposition, but according to the present study, the treatment was not effective on permitting this clinical improvement.

The difficulties in this study were that there is a taboo about the diagnosis of androgen deficiency and the fact that the ones who had androgen deficiency diagnosed did not intend to treat it. All the 40 patients were insistently sought to initiate the treatment, but there was a very low adhesion. And, the final obstacle faced by patients that went thru treatment is that testosterone gel needs a daily usage, while the injectable testosterone is made monthly or quarterly. This fact made it difficult for the patients to do an appropriate treatment.

\section{CONCLUSION}


The population in this study has high prevalence of Hipogonadism, but not qualified to be characterized as androgenic deficiency of aging male.

The treatment with testosterone gel for a mean time of 6 months was capable to significantly increase total testosterone in the subjects of this study.

Nevertheless, we suggest new research with more subjects with ADAM to confirm the benefits of the treatment with testosterone gel.

\section{Conflict of interest}

There are no conflicts of interest to declare by any of the authors of this study.

\section{Funding}

None.

\section{Authors contributions}

As we are a group that works together, all the authors made substantial contributions to conception and design, data acquisition, or data analysis and interpretation, critically revised for important intellectual content. All approved the final version of the article to be published and agreed to be accountable for all aspects of the work in ensuring that questions related to the accurancy or integrity of the work are appropriately investigated and resolved.

\section{REFERÊNCIAS}

BASHIN, S.; CUNNINGHAM, G.R.; HAYES, F.J.; MATSUMOTO, A.M.; SNYDER, P.J.; SWEFLOFF, R.S.; et al. Testosterone therapy in men with androgen deficiency syndromes: an Endocrine Society clinical practice guideline. J. Clin. Endocrinol. Metab.; 95(6):2536-59, 2010.

HARMAN, S.M.; METTER, E.J.; TOBIN, J.D.; PEARSON, J.; BLACKMAN, M.R. Longitudinal effects of aging on serum total and free testosterone levels in healthy men. Baltimore Longitudinal Study of Aging, J. Clin. Endocrinol. Metab.; 86(2):724-731, 2001 .

HAYMANA, C.; SONMEZ, A.; AYDOGDU, A.; TAPAN, S.; BASARAN, Y.; MERIC, C. et al. Effect of Testosterone Replacement Therapy on Vitamin D and FGF23 Levels in Congenital Hypogonadism. Endokrynol. Pol.; 68(3):311-616, 2017.

LIBERMAN, S.; GARCIA, Y.M.; FIGUEIRA, J.L. Andropausa/ Effects of aging in men. Rev. Bras. Med.; 68(5), 2011. 
MARTINS, A.M.; COSTA, E.M.F.; NARDI, A.C.; NARDOZZA, J.R.A.; FARIA, G.; FACIO JR, F.N. et al. Late-onset hypogonadism or ADAM: diagnosis. Rev. Assoc.

Med. Bras.; 60(4):286-294, 2014.

MARTINS, A.M.; COSTA, E.M.F.; NARDI, A.C.; NARDOZZA JR, A.; FARIA, G.; FACIO JR, F.N.; et al. Late-onset hypogonadism or ADAM: treatment. Rev. Assoc. Med. Bras.; 60(5):404-414, 2014.

MORLEY, J.E.; PERRY 3 ${ }^{\text {RD }}$, H.M.; KEVORKIAN, R.T.; PATRICK, P. Comparison of screening questionnaires for the diagnosis of hypogonadism. Maturitas; 53(4):424-429, 2006.

SURAMPUDI, P.N.; WANG, C.; SWERDLOFF, R. Hypogonadism in the Aging Male Diagnosis, Potential Benefits, and Risks of Testosterone Replacement Therapy. Int. J. Endocrinol. 0-20, 2012.

ULLAH, M.I.; RICHE, D.M.; KOCH, C.A. Transdermal testosterone replacement therapy in men. Drug Des. Devel. Ther.; 8:101-12, 2014.

WANG C, SWERDLOFF RS, IRANMANESH A, DOBS A, SNYDER PJ, CUNNINGHAM G, et al. (2000). J. Clin. Endocrinol. Metab.; 85(8):2839-53.

WANG, C.; NIESCHLAG, E.; SWERDLOFF, R.; et al. Investigation, treatment and monitoring of late-onset hypogonadism in males: ISA, ISSAM, EAU, EAA and ASA recommendations. Euro. J. Endocrinol.; Perioper; 159(5):507-514, 2008.

WU, F.C.W.; TAJAR, A.; BEYNON, J.M.; PYE, S.R.; SILMAN, A.J.; et al. Identification of Late-Onset Hypogonadism in Middle-Aged and elderly men. N. Engl. J. Med.; 363(2):123-35, 2010.

WYLIE, K.; FROGGATT, N. Late onset hypogonadism, sexuality and fertility. Hum. Fert.; 13(3):126-133, 2010. 